\title{
IMPACTO ANTRÓPICO NO PROCESSO DE ASSOREAMENTO DA ENSEADA DA JAPUÍBA, ANGRA DOS REIS (RJ)
}

ANTHROPIC IMPACT IN THE SILTING PROCESS OF JAPUÍBA BIGHT, ANGRA DOS REIS (RJ)

\author{
Yury Souto Simen VIEIRA ${ }^{1}$, Natasha Santos Gomes STANTON ${ }^{1}$, Hélio Heringer \\ VILLENA $^{2}$, Renata Cardia REBOUÇAS ${ }^{3}$ \\ ${ }^{1}$ Programa de Pós-Graduação em Oceanografia, Faculdade de Oceanografia, Hidrografia. Universidade do Estado do Rio de Janeiro. \\ E-mails: yurysimen@yahoo.com.br; natystanton@gmail.com \\ ${ }^{2}$ Faculdade de Oceanografia, Hidrografia. Universidade do Estado do Rio de Janeiro. E-mail: heliovillena@gmail.com \\ ${ }^{3}$ Faculdade de Oceanografia, Morfodinâmica Costeira. Universidade do Estado do Rio de Janeiro. E-mail: rcr.renata@ gmail.com

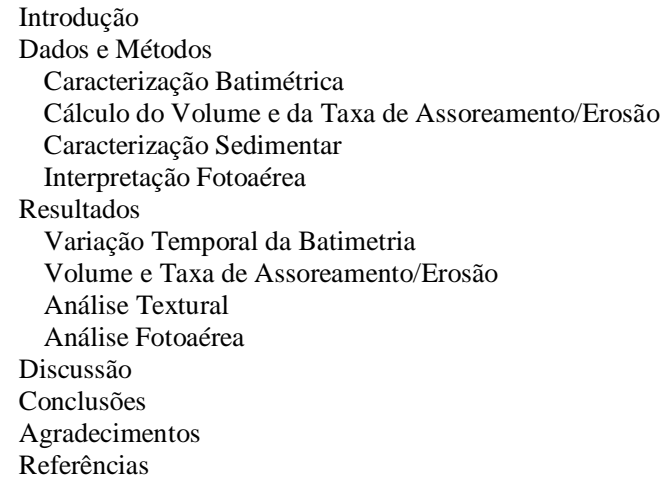

RESUMO - Foi realizado um estudo da Enseada da Japuíba, no município de Angra dos Reis, para investigar o processo de assoreamento que vem ocorrendo na região. Realizou-se levantamentos batimétricos, sedimentológicos e de acervos fotoaéreos para analisar a evolução temporal da batimetria, da textura sedimentar e de áreas de interesse nos arredores da enseada. Foram processados dados batimétricos de 1979 e de 2018, resultando em mapas comparativos de batimetria e de assoreamento/erosão. Com a análise dos sedimentos obteve-se a distribuição textural. Ocorre na enseada um processo de assoreamento, principalmente ao longo de uma zona leste - oeste em frente ao aeroporto da cidade de Angra dos Reis, próximo à linha de costa e no canal de navegação entre as ilhas Redonda e dos Bois. As principais fontes de sedimento são os rios Japuíba e Gamboa e pequenos ribeirões além do escoamento superficial devido a chuvas. O volume total de assoreamento e a taxa foram de $1.252 .642,75 \mathrm{~m}^{3} \mathrm{e} 0,97 \mathrm{~cm} /$ ano respectivamente. Propõese que significativos impactos antrópicos aumentaram o assoreamento da enseada, através de uma ocupação urbana desenfreada, do desmatamento das áreas de mangue, da retificação dos rios Gamboa e Japuíba e a remoção de suas matas ciliares e as dragagens ocorridas na enseada.

Palavras-chave: Assoreamento e Erosão; Impactos Antrópicos; Enseada da Japuíba.

\begin{abstract}
This study investigates the Japuíba Bight (Angra dos Reis municipality) aiming to characterize the process of silting up affecting the region and to infer on its causes. Bathymetric, sedimentological and photo-aerial surveys were carried out to analyze the temporal evolution of bathymetry, sedimentary texture and areas of interest in the vicinity of the bight. Bathymetric data from 1979 and 2018 were processed, resulting in comparative maps of bathymetry and silting/erosion. With the analysis of the sediments the textural distribution was obtained. It occurs in the bight a process of silting, mainly along an East-West zone in front of the Airport of the city of Angra dos Reis, proximal to the coast line along the whole study and between the Redonda and Bois islands. The results suggest that the Japuíba and Gamboa river's drainage along with smaller rivers are the main sources of sediments to the bight. The total silting volume and the rate were 1,252,642.75 $\mathrm{m}^{3}$ and $0.97 \mathrm{~cm} / \mathrm{y}$, respectively. It is proposed here that significant anthropic impact in the form of unplanned urban occupation, river form and native vegetation alterations and dredging was responsible for the process of silting up at the Japuíba Bight.
\end{abstract}

Keywords: Silting and Erosion; Anthropic Impacts; Japuíba Bight.

\section{INTRODUÇÃO}

O assoreamento é o resultado do desequilíbrio entre o aporte de material sedimentar e a capacidade de remoção do mesmo, pelos agentes dinâmicos. Em corpos d'água caracterizados pela retenção de sedimentos e por circulação hidrodinâmica pouco eficazes, como por exemplo enseadas rasas, baías, estuários e lagoas, o processo de assoreamento é potencializado
(Oliveira, 2000).

Este processo ocorre de forma natural, entretanto pode ser agravado por atividades humanas praticadas nos entornos dos corpos d'água.

As atividades antrópicas podem contribuir para o aumento da taxa de erosão e consequente o assoreamento, em até cem vezes em relação às 
condições geológicas naturais (Carvalho, 2008; Carvalho et al., 2000; Julien, 1998; Shen \& Julien, 1993).

Como exemplo de impactos antrópicos que agravam o assoreamento podemos citar: a retirada da cobertura vegetal e a ocupação do solo devido ao crescimento populacional desenfreado, o desmatamento das áreas de mangue, o despejo de materiais sólidos pela falta de esgotamento sanitário, a extração de areias do leito do rio, entre outros (Echeverria, 2007; Oliveira, 2000; Villena 1999). Essas práticas humanas contribuem para o aumento do aporte sedimentar nos ambientes deposicionais aquáticos alterando assim, o fundo desses corpos d'água, reduzindo a sua profundidade e comprometendo significativamente as condições de navegabilidade (Stevens \& Ekermo, 2003).

No Brasil, o crescimento populacional nas últimas décadas, associado ao crescente processo de desenvolvimento urbano e industrial, tem executado impactos significativos sobre os recursos naturais, principalmente a água e o solo, agravando assim processos erosivos, de assoreamento e poluidores principalmente nas zonas costeiras (Echeverria, 2007; Roig, 2005). Um impacto comumente observado são os processos de assoreamento a que estão sujeitos os ambientes deposicionais aquáticos.

A Enseada da Japuíba, localizada no interior da Baía da Ilha Grande, no município de Angra dos Reis (RJ) (Figura 1), é um importante polo turístico e pesqueiro devido as suas características naturais e vem sofrendo com o assoreamento devido à uma expansão urbana drástica das suas margens e bacias de contribuição, nos últimos 50 anos (Villena, 1999).

Este trabalho investiga os efeitos da expansão urbana no processo de assoreamento e/ou erosão em ambientes deposicionais aquáticos. Com base no exposto foi escolhida a Enseada da Japuíba como área de estudo. Os resultados e conclusões obtidos neste trabalho podem servir como uma importante ferramenta para os órgãos públicos, auxiliando nas tomadas de decisão e na adoção de contenção e mitigação do processo de assoreamento.
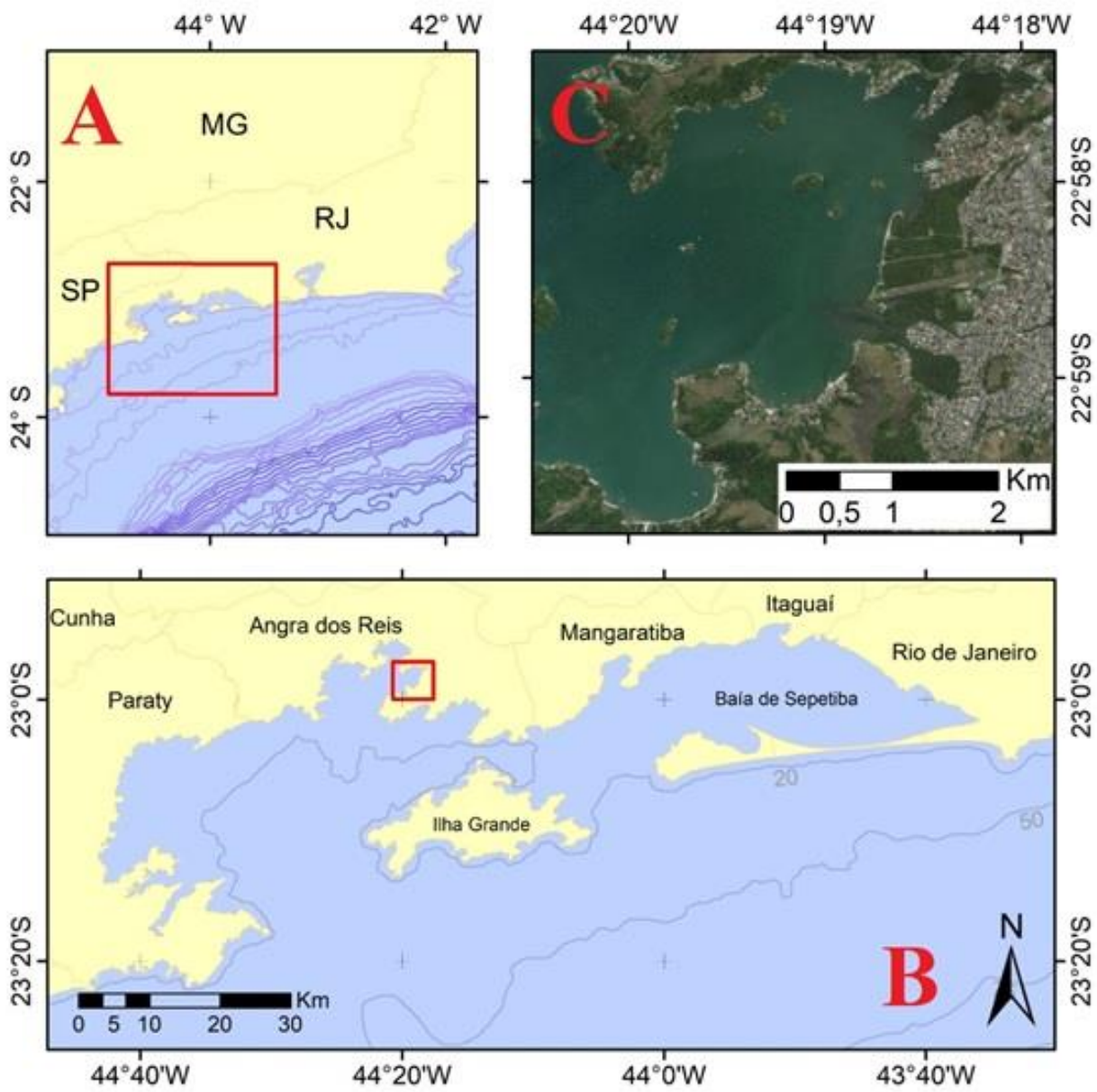

Figura 1 - Localização da Área de Estudo. (A) Mapa da Região Sudeste do Brasil destacando a Baía da Ilha Grande; (B) Mapa da Baía da Ilha Grande destacando a Enseada da Japuíba; (C) Mapa da Enseada da Japuíba (Fonte: Base cartográfica dos limites municipais - IBGE; Isóbaras batimétricas - CPRM). 


\section{DADOS E MÉTODOS}

A caracterização e mensuração do processo de assoreamento com a avaliação de possíveis causas exigem a execução de um estudo de comparação batimétrica, análise granulométrica e a identificação dos impactos antrópicos através da observação de imagens aéreas. Com base nisto, foi realizado no presente trabalho o estudo do processo de assoreamento e/ou erosão na Enseada da Japuíba, avaliando suas causas, a partir de: (i) análise da batimetria de 1979 e 2018 ditadas pela Organização Hidrográfica Internacional (OHI), evidenciando as mudanças ocorridas no relevo submerso que servirão de base para avaliar o processo de assoreamento e erosão e para o cálculo do volume e da taxa do assoreamento e erosão da enseada (1979/2018); (ii) caracterização da cobertura sedimentar e da textura sedimentar; (iii) análise da variação temporal das áreas urbanas, de mangue e dos cursos dos rios, utilizando imagens aéreas (1962 e 1991) e imagens Google Earth (2007 e 2018).

\section{Caracterização Batimétrica}

Foi utilizada no levantamento batimétrico: i) Ecobatímetro monofeixe digital ODOM de dupla frequência, modelo CV300; ii) Sistema de posicionamento DGPS Hemisphere ATLASLINK, com precisão subdecimétrica e correção diferencial por satélite (banda L); iii) Ship Motion Control modelo SMC 108; iv) Perfilador de velocidade do som ODOM modelo Digibar S. Foi utilizado como meio flutuante uma pequena traineira chamada "Lepo-Lepo" onde foi montado todo o equipamento de pesquisa.

Foi feita a correção do efeito da maré seguindo as normas ditadas pela OHI. A partir do tratamento de interpolação e da correção maregráfica dos dados batimétricos, foram elaborados os mapas batimétricos de 1979 e 2018 e o mapa de comparação de contornos batimétricos 1979 - 2018 .

\section{Cálculo do Volume e da Taxa de Assoreamento/Erosão}

A partir da subtração dos grides batimétricos de 1979 e 2018 no OASIS MONTAJ 8.4 obteve-se o mapa de assoreamento (valores positivos) e erosão (valores negativos).

Com os valores médios da taxa de assoreamento/erosão, foi realizada a distribuição espacial criando-se o mapa da taxa de assoreamento/erosão da Enseada da Japuíba.

Em seguida, foi realizado o cálculo dos volumes de assoreamento e erosão no período compreendido no levantamento, obtendo-se também, a partir da variação total ao longo do período de 39 anos, da área de estudo, a taxa de assoreamento/erosão anual para a Enseada da Japuíba.

\section{Caracterização Sedimentar}

Foram coletadas 41 amostras de sedimentos superficiais na área de estudo, utilizando um amostrador do tipo Van Veen, utilizando uma embarcação de pequeno porte para facilitar o acesso as regiões mais rasas.

Os sedimentos coletados foram submetidos à queima da matéria orgânica e carbonatos e a separação da fração grossa e lamosa por peneiramento a úmido em peneira de 4 phi. As frações grossas foram analisadas pelo processo de tamisação, onde as amostras são peneiradas a seco em peneiras de 0,5 em 0,5 phi coincidentes com os limites inferiores das classes de areia da escala de Wentworth (1922). As frações lamosas foram analisadas no Laboratório de Dinâmica de Sedimentos Coesivos (LDSC) da COPPE/UFRJ, em um analisador de partículas por difração a laser para obtenção dos percentuais dos tamanhos das partículas menores que 4 phi.

Foi realizada a análise estatística das amostras utilizando o pacote GRADISTAT 8.0 (Blott \& Pye, 2001), para realizar a classificação textural baseando-se no método proposto por Folk \& Ward (1957). A classificação textural foi convertida em classes numéricas, sendo gerado o mapa de classificação textural da Enseada da Japuíba.

\section{Interpretação Fotoaérea}

Para investigar os impactos antrópicos que ocorreram na Enseada da Japuíba, foi realizada a análise das imagens aéreas de 1962 e 1991 e do Google Earth 2007 e 2018, que permitiram mapear a variação temporal entre as áreas de mangue e as áreas urbanas.

As fotografias aéreas de 1962 e 1991 foram inseridas no Google Earth sendo ajustadas de forma a manter a mesma escala para todas as imagens, sendo georreferenciandas.

Por fim, foi definido um polígono para as áreas urbanas e de mangue e traçado o curso dos rios da enseada, realizando o cálculo das áreas totais dos polígonos criados. Estes dados forneceram a variação dos polígonos das áreas urbanas e de mangue das quatro imagens aéreas no período estudado. 


\section{RESULTADOS}

\section{Variação Temporal da Batimetria}

A comparação dos mapas batimétricos de 1979 e 2018 (Figura 2), permitiu identificar três canais: entre as ilhas Redonda e dos Bois, a NE o qual exibe uma variação da profundidade de $-5,4$ a $-2,4$ metro; um canal de menor expressão entre a Ilha dos Bois e a Ilha Pequena, com variação batimétrica entre $-4,9$ a $-1,5$ metros; ao sul da Ilha Pequena com variação batimétrica de $-3,3$ até $-1,7$ metros. É observada a presença de bancos de deposição localizados a leste próximo a linha de costa, acima de $-0,5$ metros, tornando-se exposto nas baixa-mares.

No mapa de comparação das isolinhas batimétricas de 1979 e 2018 (Figura 3) nota-se

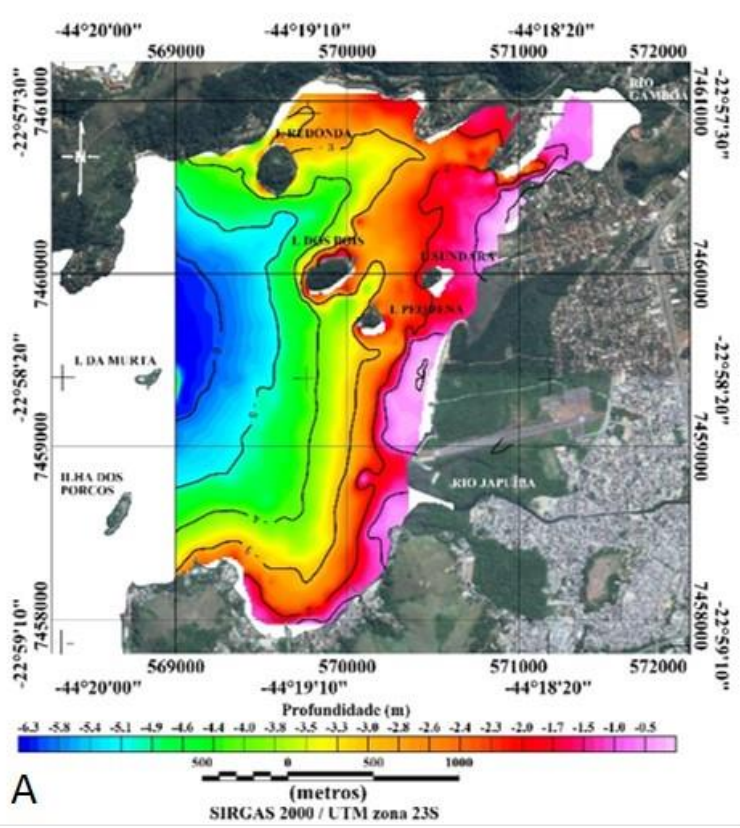

uma progradação das isolinhas em praticamente todas as profundidades, indicando que a enseada apresenta uma diminuição geral da sua profundidade. Destacam-se as mudanças nos canais entre as ilhas Redonda, dos Bois e Pequena, onde nota-se o avanço das isolinhas entre as ilhas Redonda e dos Bois, deixando o canal mais raso e indicando o assoreamento e o recuo das isolinhas entre as ilhas dos Bois e Pequena e sob a Ilha Pequena, mostrando áreas de erosão.

Também se destaca a progradação dos contornos batimétricos entre a Ilha da Murta e o aeroporto de Angra dos Reis, denotando uma grande área de assoreamento.

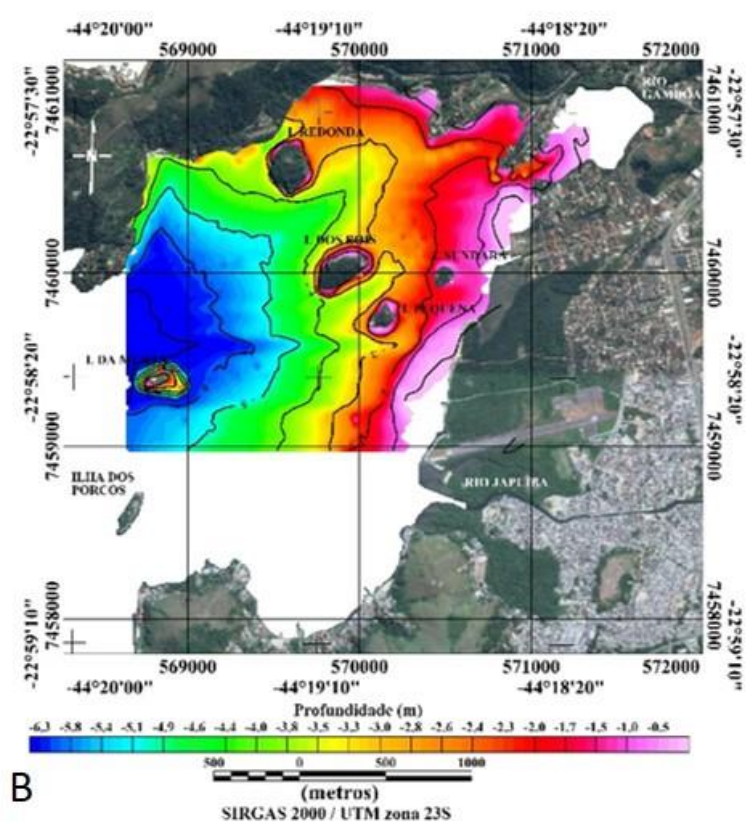

Figura 2 - Mapas batimétricos da Enseada de Japuíba de 1979 (A) e de 2018 (B).

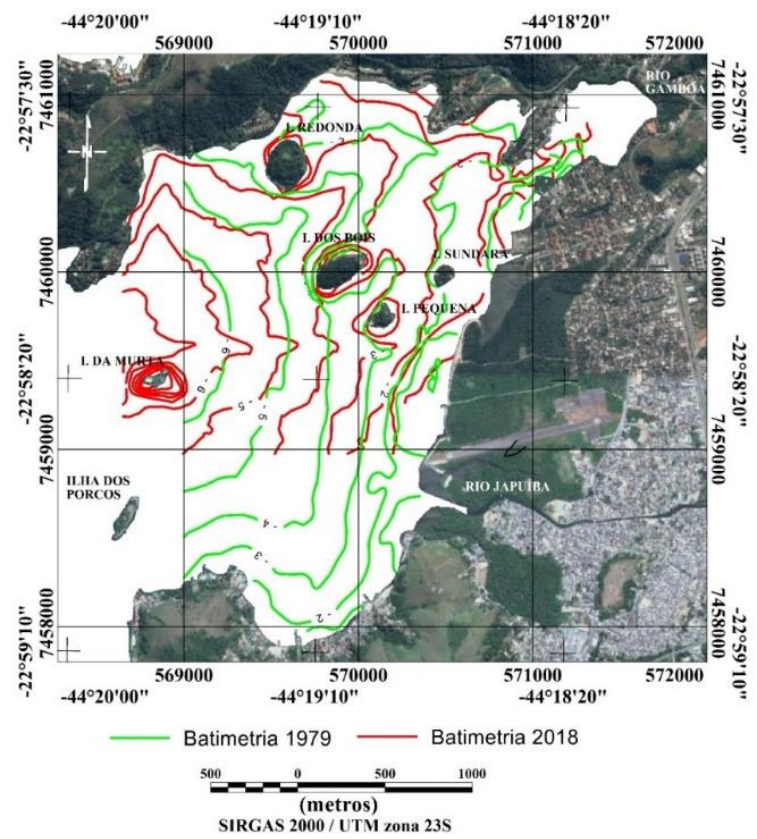

Figura 3 - Mapa de contornos batimétricos, com comparação das isolinhas entre os anos de 1979 e 2018. 


\section{Volume e Taxa de Assoreamento/Erosão}

O estudo do assoreamento e erosão da Enseada da Japuíba foi realizado, através do cálculo da diferença entre os dados referentes aos anos de 1979 e 2018, indicando quais as regiões foram mais ou menos impactadas com a deposição e remobilização dos sedimentos.

A área positiva de mais destaque fica localizada ao leste da enseada, próximo à região do aeroporto, onde ocorre uma grande zona de assoreamento chegando a quase $1 \mathrm{~m}$, estendendose no sentido Leste-Oeste. Também ocorrem áreas positivas em torno das ilhas e em

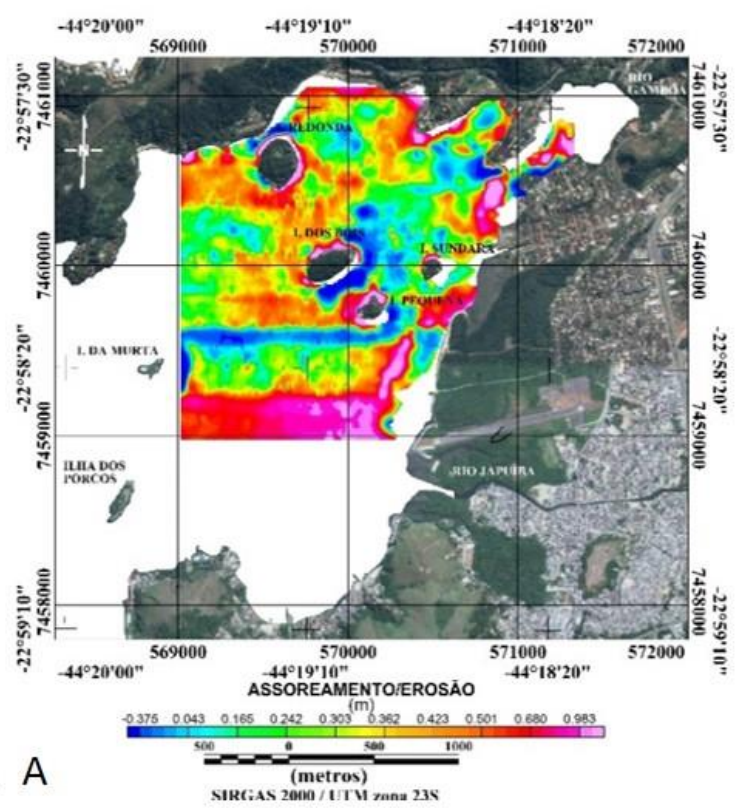

Figura 4 - A) Mapa de assoreamento/erosão 1979 - 2018

O cálculo do volume de assoreamento (valores acima do nível de referência 0) resultou em um total de $1.252 .642,75 \mathrm{~m}^{3}$. O cálculo do volume de erosão (valores abaixo do nível de referência 0) resultou em $92.644,07 \mathrm{~m}^{3}$ em um período de 39 anos.

Procedendo-se à razão entre os volumes e o tempo decorrido em anos e dividindo pela área abrangida pelo levantamento, observamos que a taxa de assoreamento e a taxa de erosão correspondem à $0,97 \mathrm{~cm} / \mathrm{ano}$ e $0,07 \mathrm{~cm} / \mathrm{ano}$, respectivamente.

\section{Análise Textural}

O mapa da classificação textural (Figura 5) indica que quase toda a enseada exibe a predominância de sedimentos finos como silte. Das 41 amostras analisadas, 24 são compostas por silte, porém são encontradas amostras em outras classificações como areia, areia siltosa e silte arenoso.

$\mathrm{Na}$ região Leste próximo à linha de costa ocorrem sedimentos mais grossos como areia e proximidade à linha de costa com valores variando de $16 \mathrm{~cm}$ até aproximadamente $1 \mathrm{~m}$ (Figura 4.A).

Algumas áreas negativas se evidenciam, tais como os canais entre as ilhas dos Bois e Pequena, uma região ao nordeste da enseada próximo ao Rio Gamboa e uma longa faixa Leste-Oeste que cruza toda a enseada.

A maior taxa de assoreamento corresponde à aproximadamente $3,8 \mathrm{~cm}$ de sedimentos depositados anualmente. Já a maior taxa de erosão corresponde a $2,7 \mathrm{~cm}$ de sedimentos por ano (Figura 4.B).

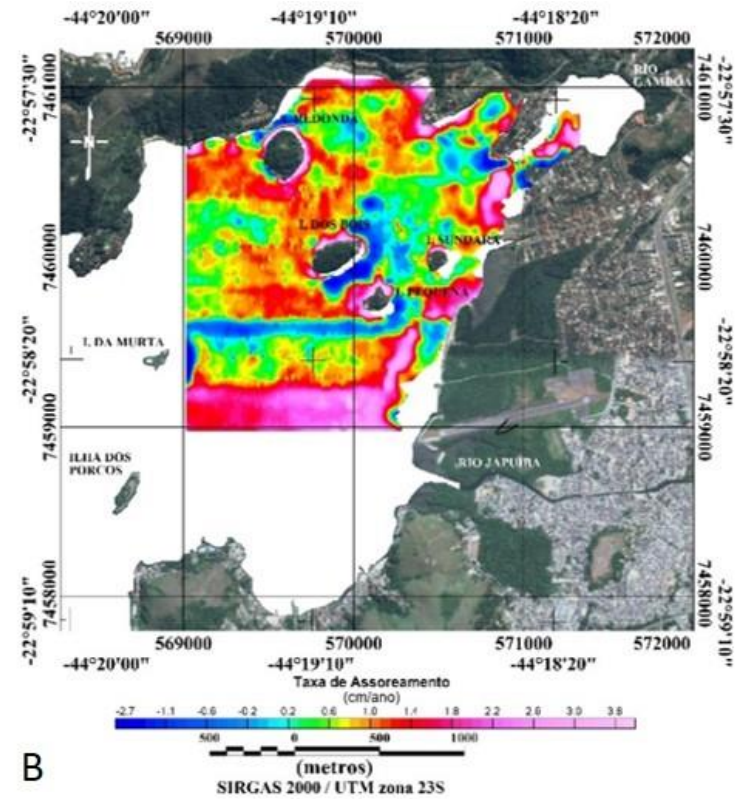

areia siltosa, devido à proximidade com a foz do Rio Japuíba e de pequenos rios que desaguam na enseada indicados por setas brancas no mapa de classificação textural (Figura 5).

Também se destaca na enseada o silte arenoso, que se encontra no canal sul da enseada, próximo ao Rio Gamboa e na parte noroeste da enseada.

\section{Análise Fotoaérea}

Foram analisadas as imagens aéreas da Enseada da Japuíba entre o período de 1962 a 2018 (Figura 6) visando a comparação qualitativa e quantitativa da ocupação urbana, alteração das áreas de mangue e dos cursos dos rios no período supracitado. Essa análise permite avaliar as mudanças antrópicas ocorridas e serve de base para entendermos as mudanças na batimetria e o assoreamento da área de estudo.

Na imagem aérea de 1962 (Figura 7), observase a área de mangue (verde) e poucas construções como o aeroporto, a estrada e algumas edificações (vermelha). As fotos aéreas dos períodos 
posteriores (Figura 7) exibem profundas porção nordeste da enseada e uma área na parte sul. alterações no meio ambiente.

Também pode-se observar uma restrição da

A planície sedimentar, em sua maior parte, é área de mangue na região ao norte do aeroporto, ocupada pela área urbana e o mangue é restrito ao sendo este substituído por vegetação nativa do entorno do aeroporto, duas pequenas faixas na continente adjacente à enseada.

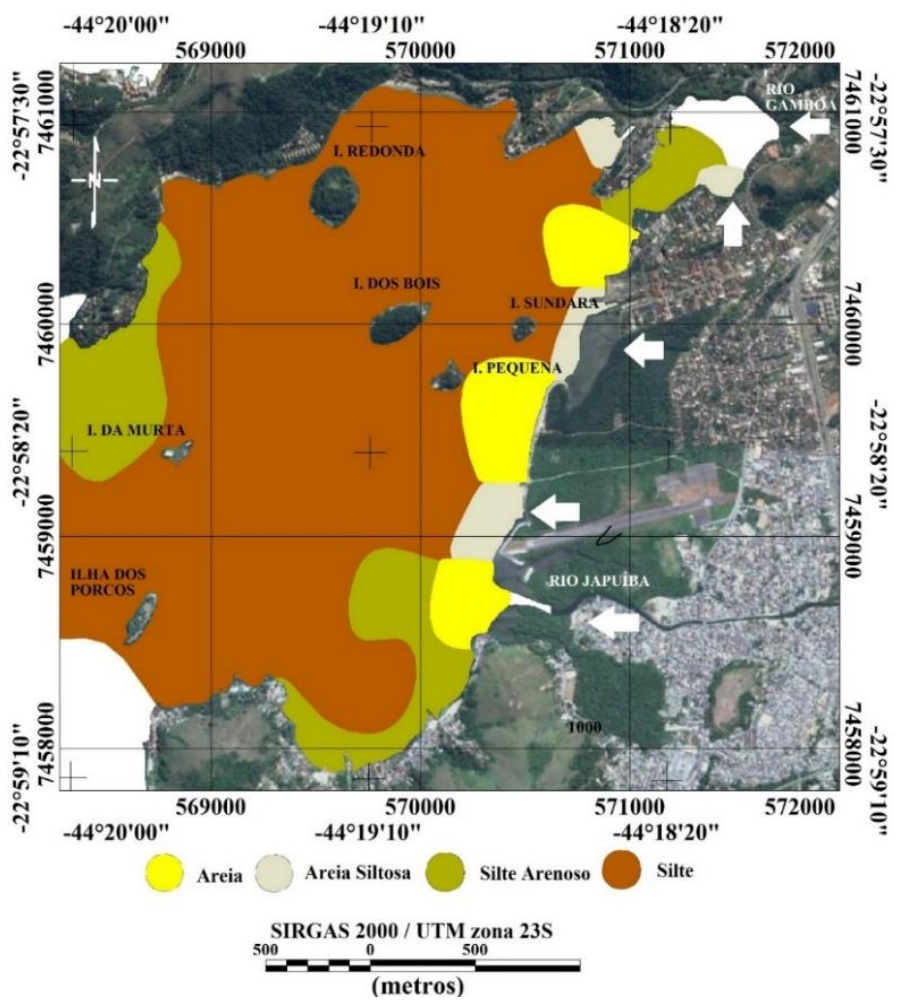

Figura 5 - Mapa de Classificação Textural dos Sedimentos da Enseada da Japuíba.
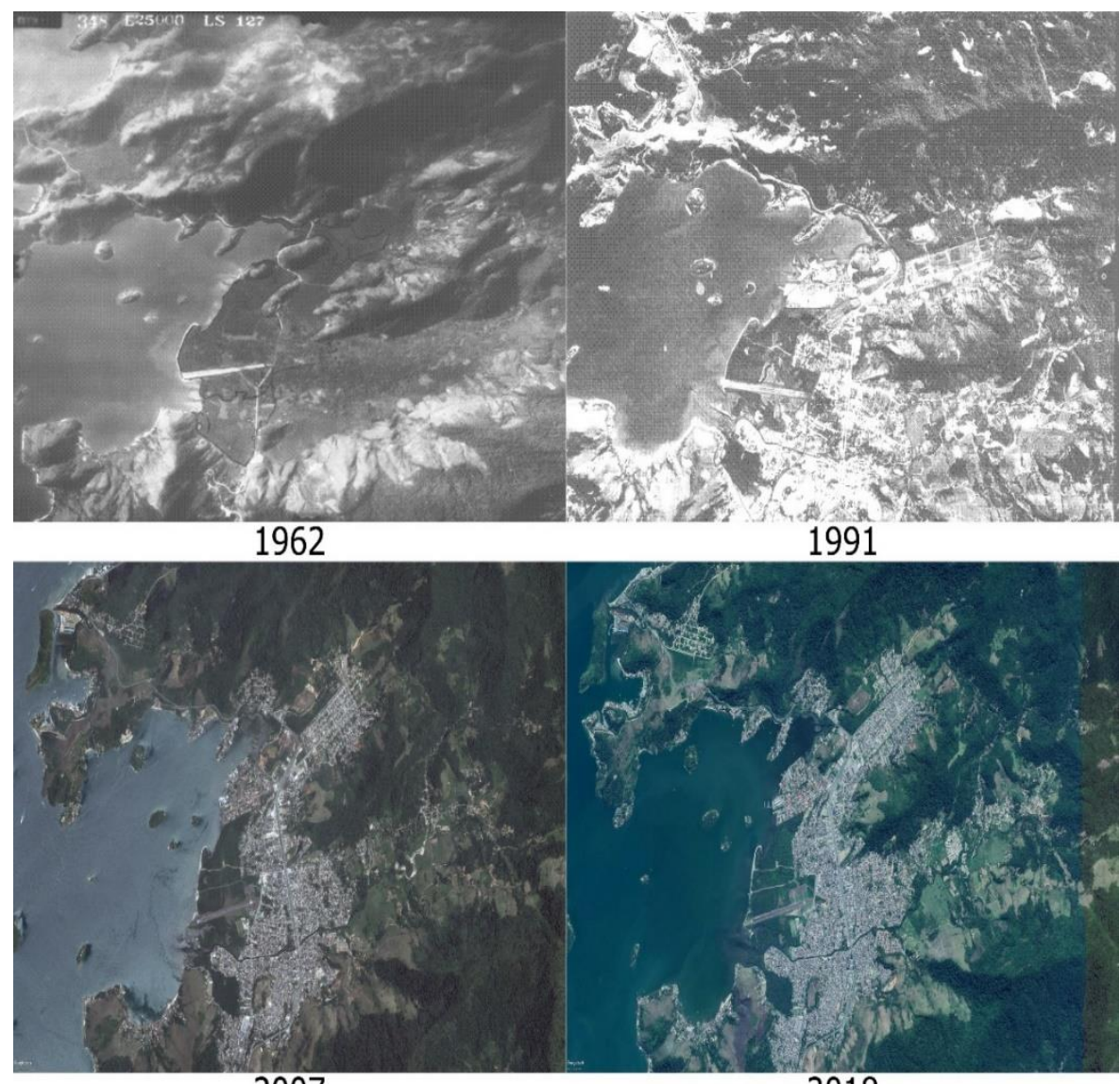

2007

2018

Figura 6 - Imagens aéreas brutas de 1962, 1991, 2007 e 2018. 


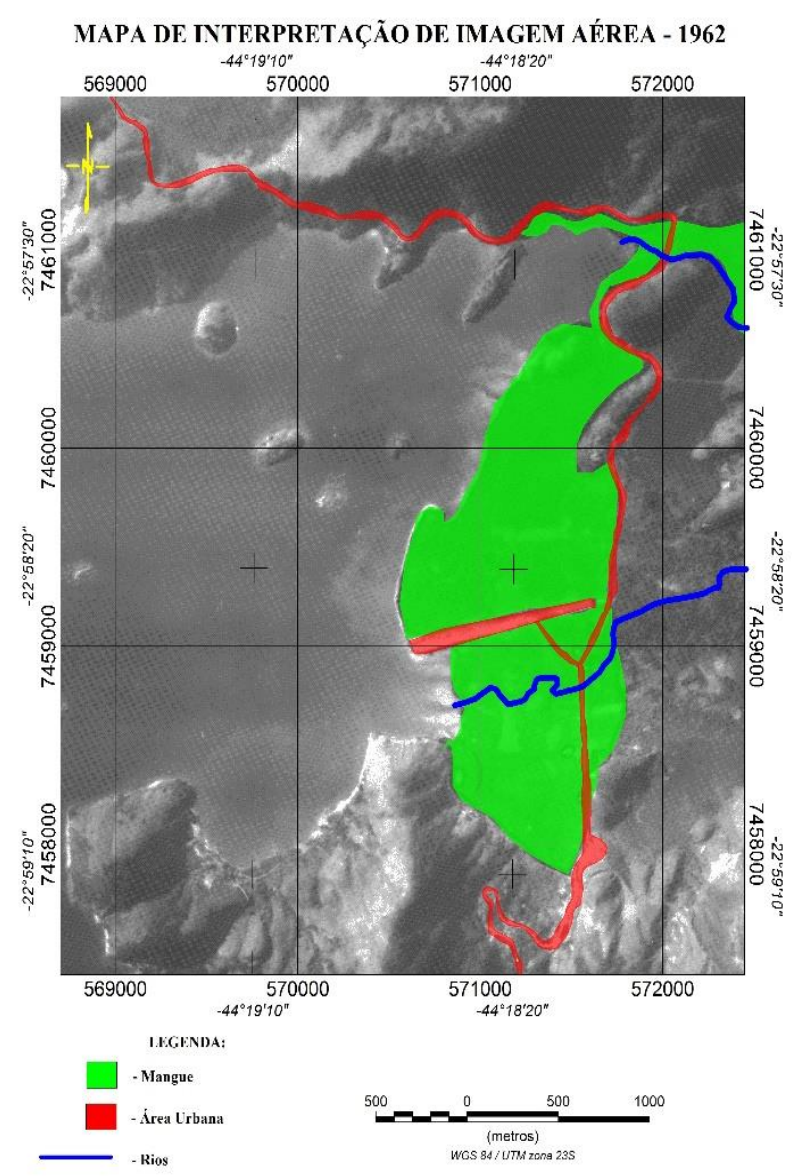

MAPA DE INTERPRETAÇÃO DE IMAGEM AÉREA - 1991
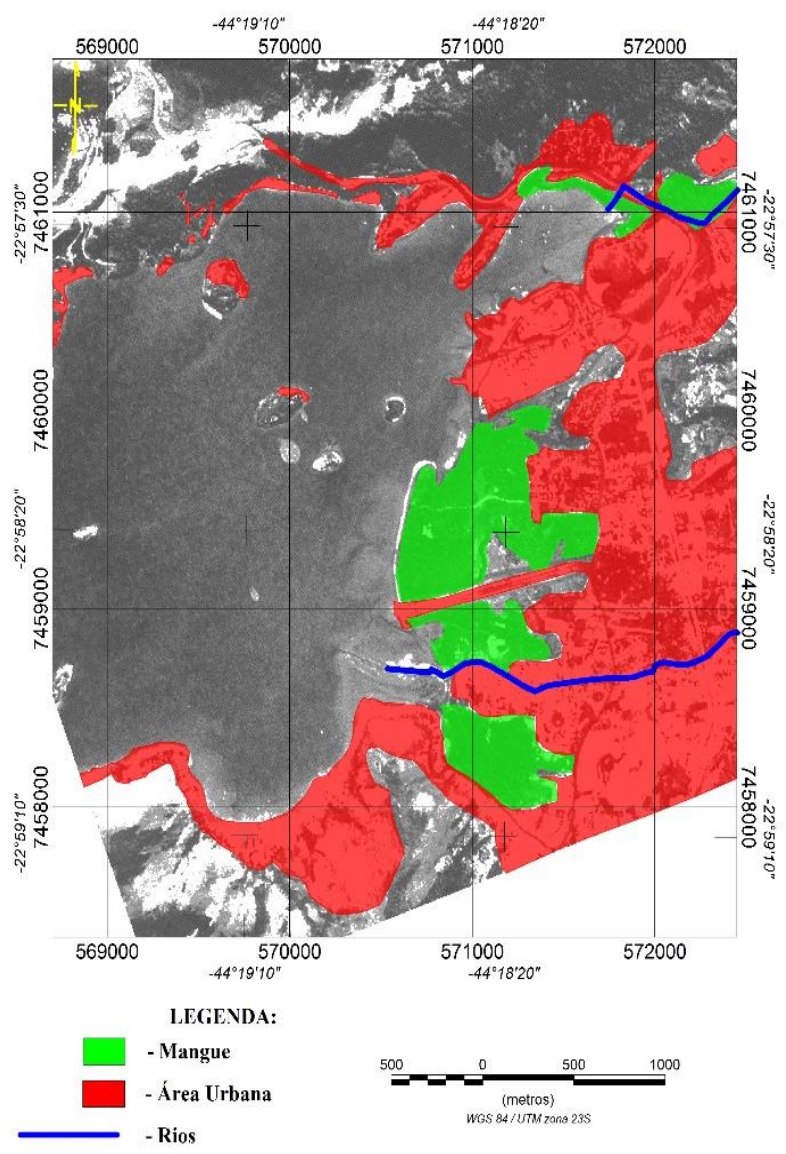

MAPA DE INTERPRETAÇĀO DE IMAGEM AÉREA - 2007

\section{MAPA DE INTERPRETAÇÃO DE IMAGEM AÉREA - 2018}
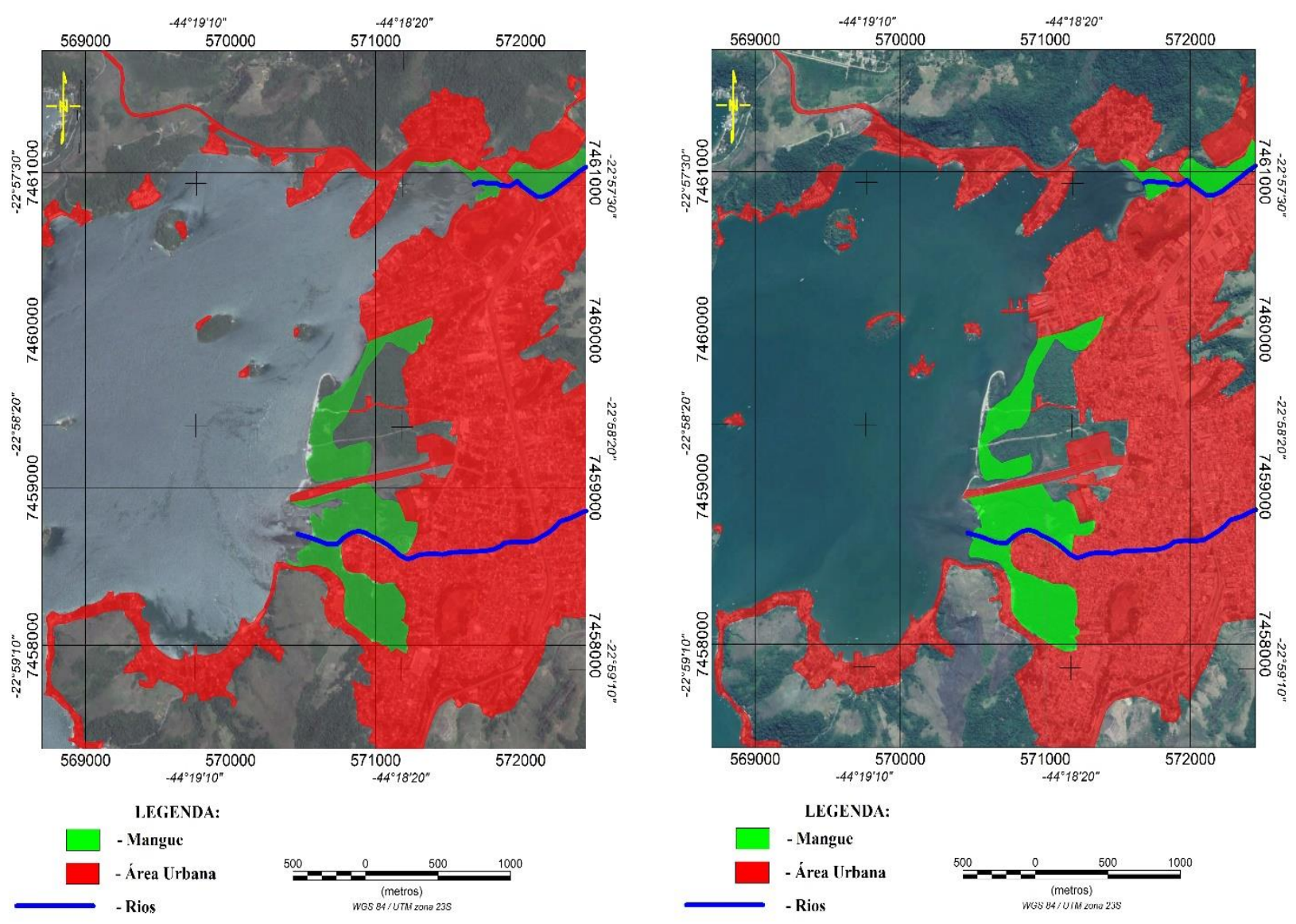

Figura 7 - Imagens aéreas interpretadas de 1962, 1991, 2007 e 2018. 
Em contrapartida, na região próxima ao Rio Japuíba as áreas de mangue estão avançando em direção as áreas assoreadas. Em 1962 os rios eram meandrantes e mantinham a sua mata ciliar; nos anos seguintes, os rios tiveram o seu curso alterado, seus meandros retilinizados e suas matas ciliares praticamente eliminadas.

\section{DISCUSSÃO}

A partir da caracterização batimétrica, sedimentológica e da análise fotoaérea foi possível mapear os locais de ocorrência de assoreamento na Enseada da Japuíba. Foram identificadas áreas de assoreamento, localizadas na faixa Leste - Oeste próximo ao aeroporto de Angra dos Reis, bem como ao longo da linha de costa de toda a enseada. As principais zonas de erosão encontram-se na faixa desde o norte da Ilha da Murta até o cais da cidade e do aeroporto, nos canais de navegação entre as ilhas dos Bois e Pequena e em alguns pontos ao norte da enseada próximo à linha de costa. Os sedimentos refletem na sua composição textural e na sua distribuição espacial os processos deposicionais. Foi observado que os sedimentos mais grossos estão próximos às desembocaduras dos rios Gamboa e Japuíba e a pequenos rios da região e os sedimentos mais finos estão nas porções mais distais onde a hidrodinâmica é menos elevada. As imagens fotoaéreas indicaram mudanças na cobertura vegetal e de ocupação urbana, que representam as ações antrópicas que o entorno da enseada sofreu nos últimos 52 anos, incluindo o processo de urbanização sem planejamento, o desmatamento das áreas de mangue e a remoção da mata ciliar (Figura 8).

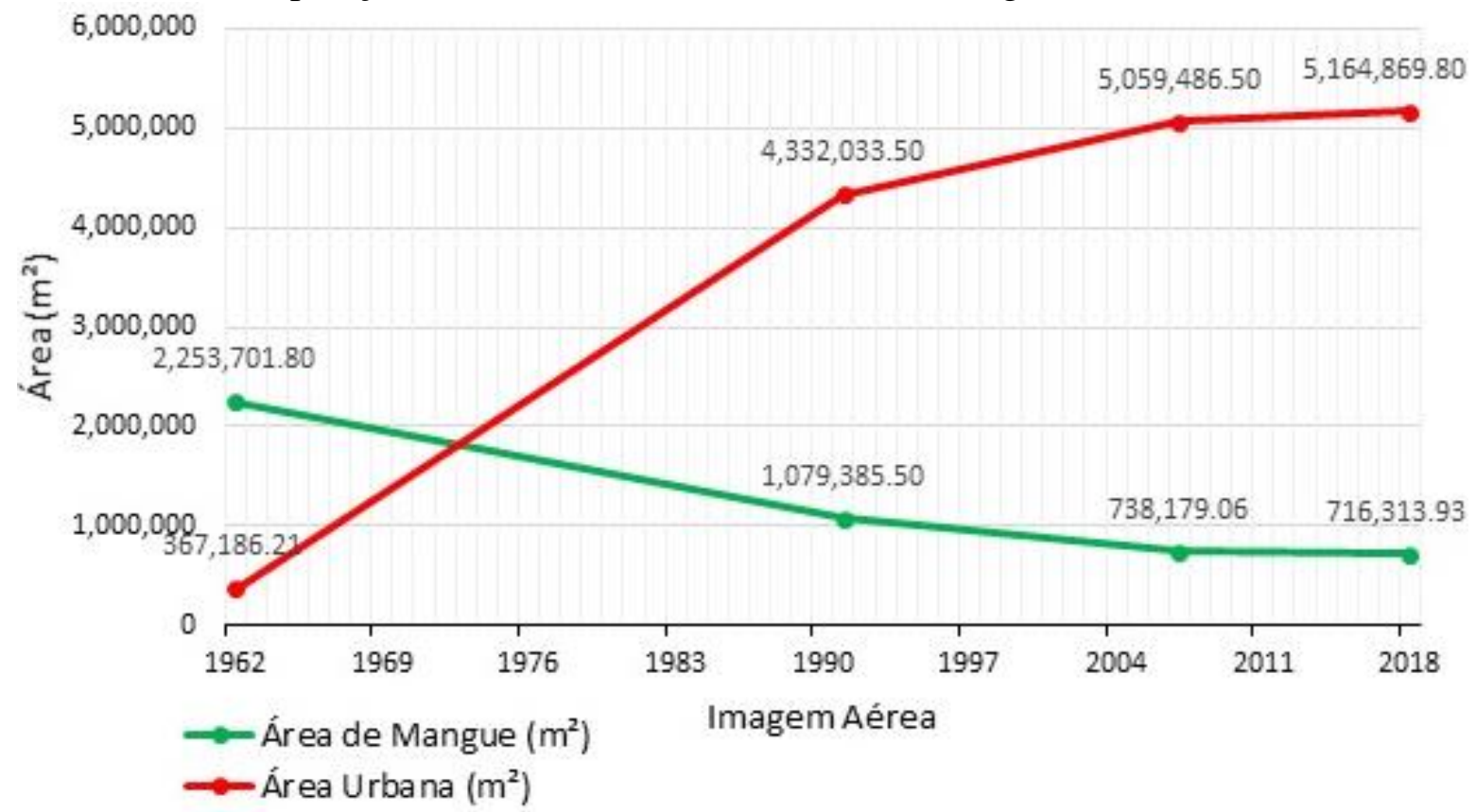

Figura 8 - Gráfico com a relação das áreas dos polígonos das imagens aéreas interpretadas, considerando áreas de mangues X áreas urbanas.

Para uma melhor visualização das mudanças ocorridas nos últimos 39 anos na Enseada da Japuíba foram plotados 4 perfis batimétricos comparativos dos dados de 1979 e 2018. (Figura 9).

O perfil 01 (Figura 9) constata-se que houve assoreamento em toda a seção, dando o maior destaque a área próxima ao Rio Gamboa chegando a quase 1 metro evidenciando assim, o rápido assoreamento neste local devido à proximidade com a área de origem.

No perfil 02 (Figura 9) se observa uma alternância entre os processos de assoreamento e de erosão ao longo do canal entre as ilhas dos Bois e Pequena. Também se nota no final deste perfil uma área de intenso assoreamento onde ocorre um abrupto nivelamento entre as batimetrias e em seguida, o assoreamento destaca-se. Especula-se que nessa região o fundo marinho tenha sido alterado por dragagens para a passagens de embarcações na foz do rio Gamboa.O perfil 03 (Figura 9) exibe a mudança da batimetria no canal de navegação entre a Ilha Redonda e a Ilha dos Bois. Nota-se um quase nivelamento dos dois perfis estando o perfil de 2018 sempre acima do 1979 evidenciando o assoreamento. Este ganha mais destaque próximo à linha de costa onde o assoreamento chega até um metro. 

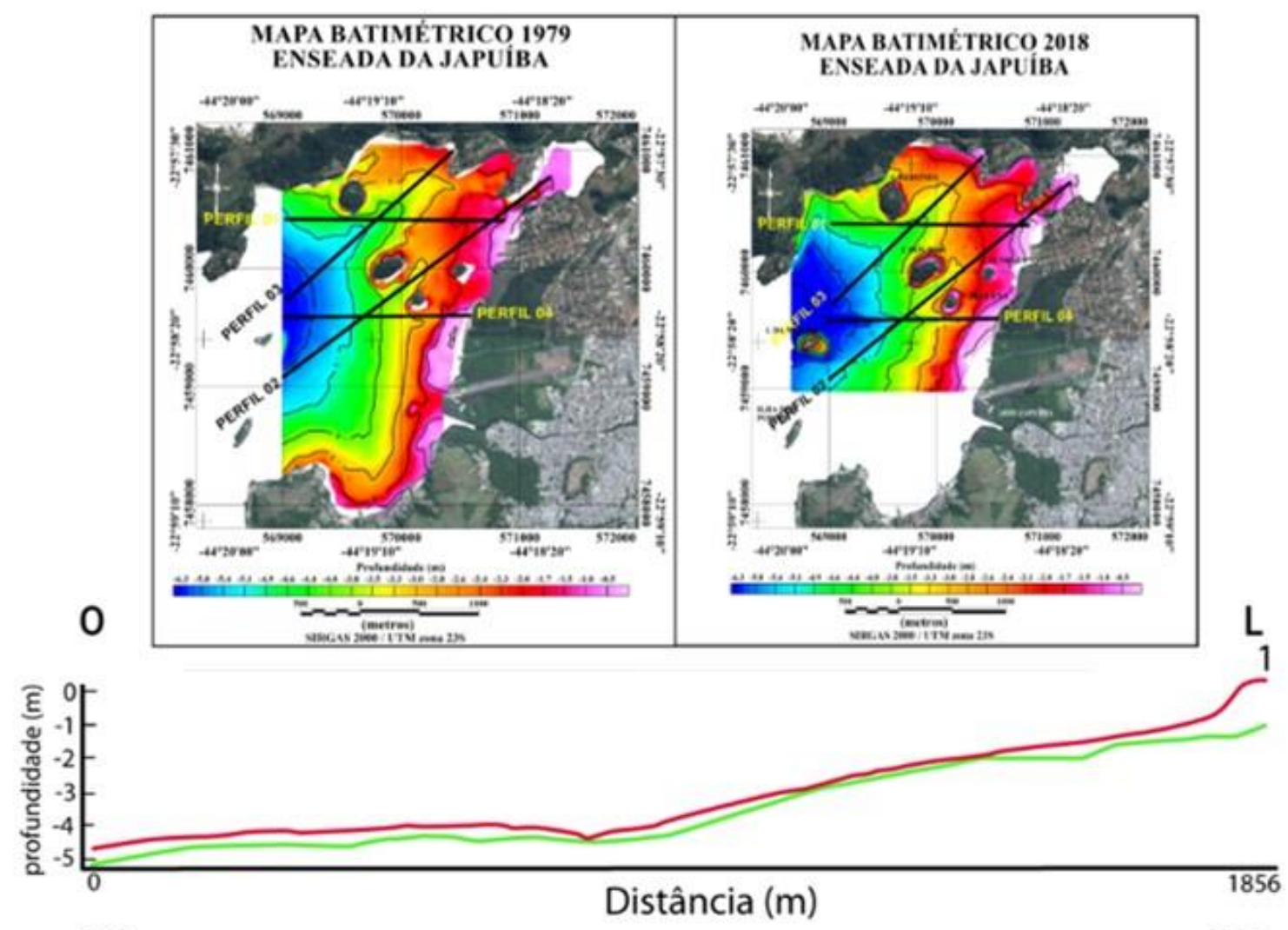

so

$\mathrm{NE}$

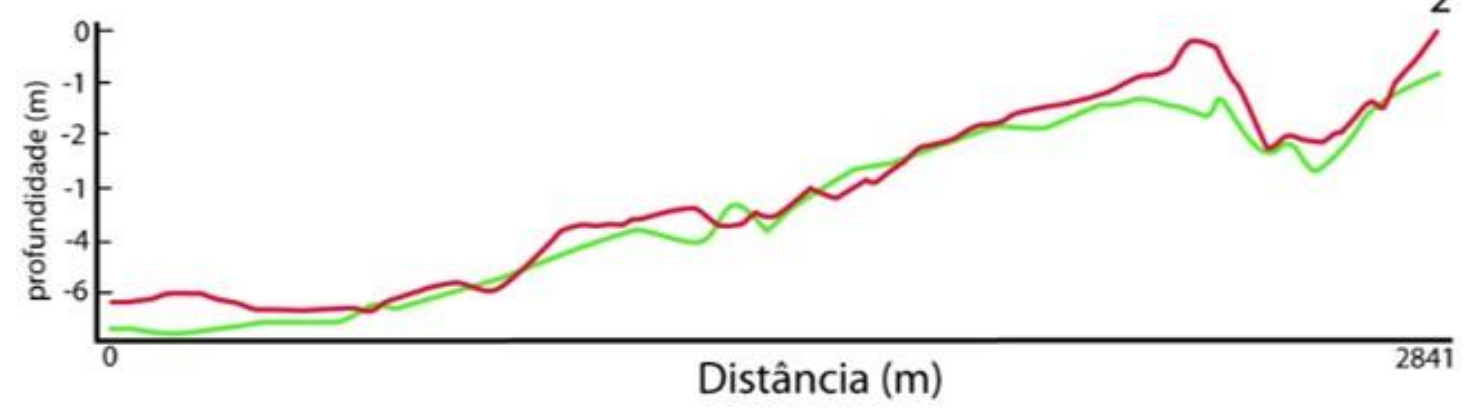

so

$\mathrm{N} \mathrm{E}$
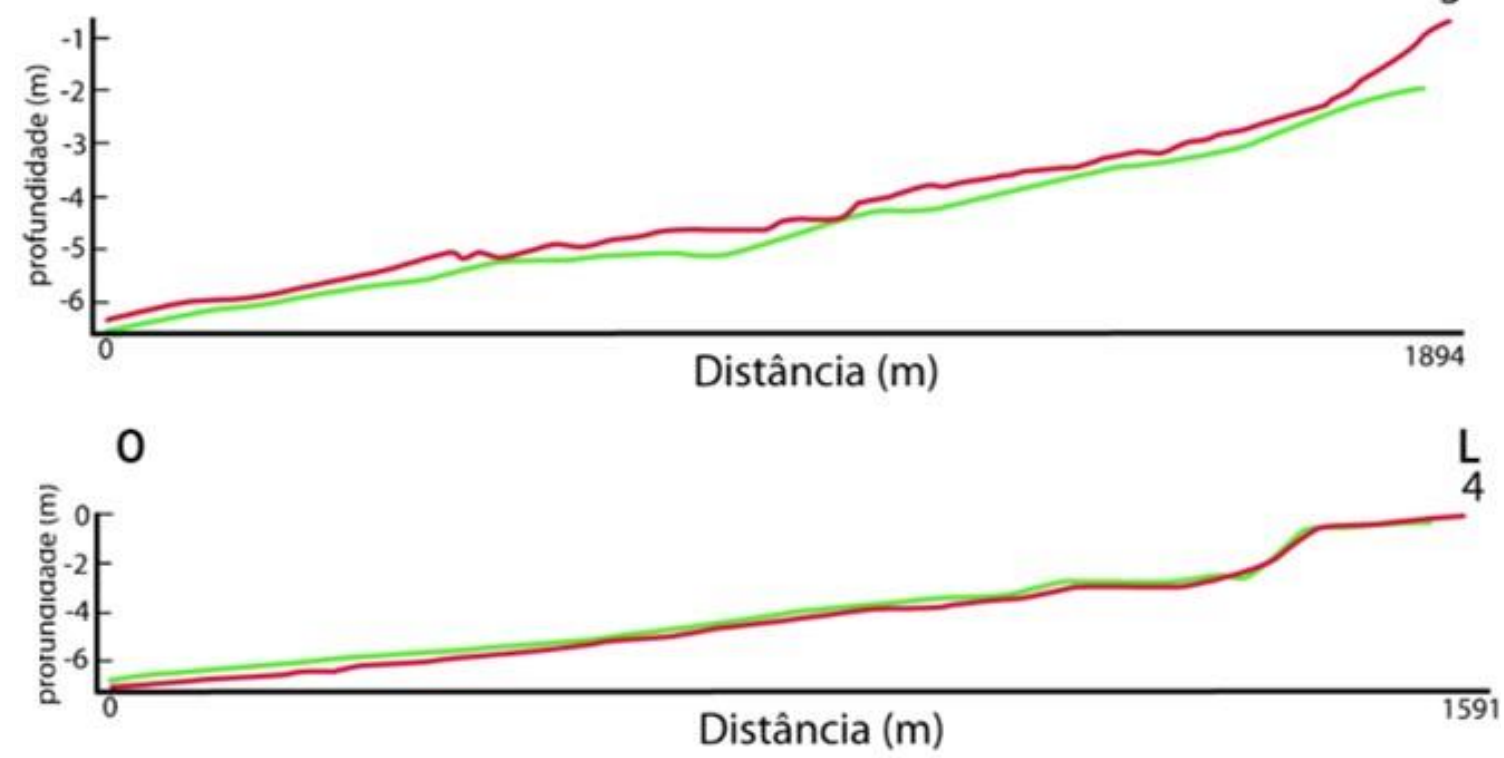

batimetria de 1979

batimetria de 2018

Figura 9 - Perfis batimétricos de 1979 e 2018. 
O perfil 04 (Figura 9) foi plotado na grande faixa de erosão que corta toda a enseada desde o norte da Ilha da Murta até o cais da cidade e do aeroporto.

Fica evidente a erosão observando-se que a batimetria de 1979 apresenta valores mais rasos em relação à batimetria de 2018 em quase todo o perfil, atingindo níveis muito próximos junto à linha de costa.

Julga-se que essa faixa não resulta de processos, uma vez que apresenta uma configuração totalmente retilínea.

Especula-se que essa região seja resultado de dragagens para a passagem de embarcações até o cais da cidade e do aeroporto de Angra dos Reis. Infelizmente não foi possível obter os dados de dragagens na região para confirmar tal hipótese.

A taxa de assoreamento da Enseada da Japuíba condiz com outros estudos onde o assoreamento apresenta níveis muito altos.

Saito et al. (2001) relata valores de até 0,98 $\mathrm{cm} /$ ano no sistema estuarino de Cananeia Iguapé, valor próximo ao do presente estudo $(0,97 \mathrm{~cm} / \mathrm{ano})$.

No estuário de Santos, os valores estimados por Figueira et al. (2004) ficam entre 0,16 a 0,54 $\mathrm{cm} / \mathrm{ano}$ e na Baia de Guanabara, Oliveira et al. (2004) observou taxas de assoreamento de 0,89 $\mathrm{cm} /$ ano, abaixo do encontrado neste trabalho.

Em contrapartida, o estudo de Odreski et al. (2003) na Baia de Antonina encontrou uma taxa de assoreamento de 2,6 cm/ano e Azevedo et al. (2016) estimou taxas de 1,6 cm/ano nas planícies de maré de São Luís, valores acima encontrados neste estudo.

A integração dos resultados com as análises sedimentológicas indica que na porção leste da enseada, o intenso assoreamento observado está associado a faixas de areia. Isso ocorre provavelmente devido à proximidade com os rios Gamboa, Japuíba e pequenos rios, formando bancos arenosos locais.

As outras zonas de assoreamento estão associadas aos sedimentos lamosos e podem resultar da hidrodinâmica da enseada.

Uma vez que os sedimentos mais finos são normalmente depositados em ambientes de baixa energia, acredita-se que estes se depositaram a maiores distâncias da fonte na enseada, que possui uma hidrodinâmica de baixa energia.

Acredita-se que esses sedimentos podem ser oriundos dos rios Gamboa e Japuíba ou trazidos pelo escoamento superficial causado por chuvas na região.

Propõe-se, a partir da integração das evidências apresentadas que as causas do assoreamento na Enseada da Japuíba se devem a ações antrópicas, que teriam ocasionado um aumento do carreamento dos sedimentos do continente, relacionado a um processo de urbanização sem planejamento.

Dentre as principais ações antrópicas se destacam: i) a retificação dos rios Gamboa e Japuíba, com a remoção das suas matas ciliares, afetando a dinâmica sedimentar, uma vez que as suas redes de drenagem, juntamente com pequenos rios e o escoamento superficial, são as principais fontes de sedimentos para a Enseada da Japuíba; ii) o desmatamento e aterro das áreas de mangue demonstrando uma perda significativa da sua vegetação, sendo substituída em alguns locais por vegetação continental; iii) a continuidade das dragagens para passagens de embarcação, principalmente nas áreas próximas ao aeroporto de Angra dos Reis e na foz dos rios Gamboa e Japuíba, podendo alterar a hidrodinâmica local; iv) o crescimento da extração de areias do leito dos rios devido o assoreamento do mesmo.

\section{CONCLUSÕES}

No presente estudo foi realizado um levantamento de dados com o objetivo de verificar a ocorrência do assoreamento na Enseada da Japuíba. A partir da integração da análise geofísica e geológica, avaliou-se as variações batimétricas ocorridas ao longo de 39 anos, a distribuição sedimentar, as mudanças na ocupação humana e as alterações na vegetação, pode-se constatar que está ocorrendo um processo de assoreamento na Enseada da Japuíba. Aponta-se aqui que este processo está relacionado, principalmente, a um desequilíbrio no aporte sedimentar causado por ações antrópicas.

Tais ações geram um aumento no carreamento dos sedimentos, pelo processo de urbanização sem planejamento, conforme observado na região. Destacam-se entre as principais ações causadoras: a retificação dos cursos dos rios Japuíba e Gamboa, a remoção da mata ciliar juntamente com a extração de areia destes rios e o desmatamento das áreas de mangue. 


\section{AGRADECIMENTOS}

Os autores agradecem a CAPES (Coordenação de Aperfeiçoamento de Pessoa de Nível Superior) por permitir o custeio da bolsa de estudos e a Sub-Reitoria de Graduação (SR1), a Diretoria de Administração Financeira (DAF) e ao Programa de Pós-Graduação em Oceanografia da UERJ (Universidade do Estado do Rio de Janeiro) pelo apoio financeiro.

\section{REFERÊNCIAS}

AZEVEDO, J.W.J.; CASTRO, A.C.L.; SANTOS, M.C.F.V Siltation rate and main anthropic impacts on sedimentation of the São Luís tidal inlet - State of Maranhão, Brazil. Brazilian Journal of Oceanography, v. 64, n. 1, p. $9-18,2016$.

BLOTT, S.J. \& PYE K. GRADISTAT: a grain size distribution and statistics package for the analysis of unconsolidated sediments, Earth Surface Processes and Landforms, v. 26, n. 11, p. 1237 - 1248, 2001.

CARVALHO, N.O. (Coordr). Hidrossedimentologia Prática. Rio de Janeiro: Interciência, 559 p., 2008.

CARVALHO, N.O.; FILIZONA, N.P.; SANTOS, P.M.C.; LIMA, J.E.F.W. (Coordenadores). Guia de Avaliação de Assoreamento em Reservatórios. Brasília: ANEEL, 132 p., 2000.

ECHEVERRIA, R.M. Avaliação de Impactos Ambientais nos Tributários do Lago Paranóa, Brasília - DF, 2007. 132 p. Dissertação (Mestrado em Geologia) - Universidade de Brasília.

FIGUEIRA, R.C.L.; TESSLER, M.G.; MAHIQUES, M.M.; FUKUMOTO, M.M.; GOYA, S.C. Sedimentação recente e níveis de metais pesados em testemunhos do estuário santista. In: CONGRESSO DE PESQUISAS AMBIENTAIS E SAÚDE, 4, Santos, 2004. In: Anais...Santos, 2004

FOLK, R.L. \& WARD, W.C. Brazos River Bar: a study in the significance of grain parameters. Journal of Sedimentary Research, v. 27, n. 1, p. 3-26, 1957.

JULIEN, P.Y. (Coordr). Erosion and Sedimentation. Crambridge: Cambridge University Press, 277 p., 1998.

ODRESKI, L.L.R.; SOARES, C.R.; ÂNGULO, R.J.; ZEM, R.C. Taxas de assoreamento e a influência antrópica no controle da sedimentação da Baía de Antonina. Boletim Paranaense de Geociências, v. 53, p. 7 - 12, 2003

OLIVEIRA, G.H.R.; PATCHINEELAM, T.C.S.; PATCHINEELAM, S.M. Validação do método de geocronologia de ${ }^{210} \mathrm{~Pb}$ por espectrometria gama utilizando o detector coaxial de GE ultrapuro do Departamento de Geoquímica da UFF. In: SIMPÓSIO BRASILEIRO DE OCEANOGRAFIA, 2, 2004, São Paulo. Anais...São Paulo, 2004.
OLIVEIRA, L.V. Assoreamento na Ilha de Paquetá (RJ), Rio de Janeiro. 2000. 41 p. Dissertação (Mestrado em Geologia e Geofísica Marinha), Instituto de Geociências. Universidade Federal Fluminense.

ORGANIZAÇÃO HIDROGRÁFICA INTERNACIONAL. Especificações da OHI para levantamentos batimétricos. Disp.em: https://www.iho.int/iho_pubs/standard/S44_Ed\%205\%200\%200_PT-BR\%20\%282\%29.pdf Acessado em: 10ago2018

ROIG, H.L. Modelagem e integração de processos erosivos e do transporte de sedimentos - $O$ caso da Bacia do Rio Paraíba do Sul - SP, 2005. 206p. Tese (Doutorado), Instituto de Geociências. Universidade de Brasília.

SAITO, R.T.; FIGUEIRA, R.C.L.; TESSLER, M.G.; CUNHA, I.I.L. ${ }^{210} \mathrm{~Pb}$ and ${ }^{137} \mathrm{Cs}$ geochronologies in the Cananéia-Iguape estuary. Journal of Radioanalytical and Nuclear Chemistry, v. 249 , n. 1 , p. $257-261,2001$.

SHEN, H.W. \& JULIEN, P.Y. Erosion and Sediment Transport. In: D. R. Maindmant (Coordenador), Handbook of Hidrology, p. $452-472,1993$.

STEVENS, R.L. \& EKERMO, S. Sedimentation and erosion in connection with ship traffic, Göteborg Harbour, Sweden. In: Enviromental Geology, p. 466 - 475, 2003.

VILLENA, H.H. Caracterização do Processo de Assoreamento na Enseada da Japuíba - Angra dos Reis - RJ. Rio de Janeiro. 1999. 127 p. Dissertação (Mestrado em Geologia e Geofísica Marinha), Departamento de Geologia. Universidade Federal Fluminense.

WENTWORTH, C.K. A scale of grade and class terms for clastic sediments. The Journal of Geology, v. 30, n. 5, p. 377 - 392, 1922. 